\title{
Formation of hydrogen molecules in crystalline silicon
}

\author{
A.W.R. Leitch ${ }^{\mathrm{a}, *}$, J. Weber ${ }^{\mathrm{b}}$, V. Alex ${ }^{\mathrm{b}}$ \\ ${ }^{a}$ Department of Physics, University of Port Elizabeth, PO Box 1600, Port Elizabeth 6000, South Africa \\ ${ }^{\mathrm{b}}$ Max-Planck-Institut für Festkörperforschung, Heisenbergstrasse 1, D-70569 Stuttgart, Germany
}

\begin{abstract}
Molecular hydrogen was directly observed by Raman spectroscopy in silicon samples subjected to a hydrogen plasma. At lower hydrogen plasma temperatures $\left(\sim 150^{\circ} \mathrm{C}\right)$ the hydrogen molecules form at tetrahedral interstitial sites within the Si lattice. For higher temperatures $\left(>150^{\circ} \mathrm{C}\right)$ the plasma treatment results in hydrogen related platelets which act as sinks to which the molecules diffuse. Once trapped within the extended voids created by the platelets, the $\mathrm{H}_{2}$ molecules exhibit a vibrational frequency that is practically the same as the well-known value for gaseous $\mathrm{H}_{2}$. (C) 1999 Elsevier Science S.A. All rights reserved.
\end{abstract}

Keywords: Raman scattering; Silicon; Hydrogen

\section{Introduction}

The behaviour of hydrogen in $\mathrm{Si}$ is a subject of considerable technological importance, because of the various ways in which hydrogen may interact with the defects and impurities in the $\mathrm{Si}$, thereby modifying the electrical properties of the material [1]. A simple example that has received much attention in recent years is the passivation by hydrogen of the shallow donors and acceptors in doped $\mathrm{Si}$, leading to an increase in the specific resistivity. Although not as well understood, hydrogen also forms complexes with many deep defects in the $\mathrm{Si}$.

Hydrogen is also known to be responsible for the introduction of defects into the Si. Several observations of platelet-like precipitation of hydrogen in $\mathrm{Si}$ have been reported [2-5]. Although no detailed model of hydrogen platelet formation in Si has been completely accepted, it is most likely that the platelets form through the hydrogen passivation of $\mathrm{Si}-\mathrm{Si}$ bonds broken at the type I (111) plane during the hydrogen introduction process $[5,6]$. Transmission electron microscopy (TEM) studies have indicated that a considerable number of $\mathrm{H}_{2}$ molecules may be in the open space between the platelets and that the pressure of the hydrogen can be of the order of $1 \mathrm{GPa}$ [5].

* Corresponding author. Tel.: +27-41-5042219; fax: + 27-415042573; e-mail: phaawl@upe.ac.za.
Hydrogen is often unintentionally introduced into the silicon during crystal or epitaxial growth as well as during subsequent processing steps such as standard wet chemical etching, plasma etching and thermal treatments. Hydrogen may also be intentionally introduced by means of implantation and plasma treatments. If the hydrogen concentration in $\mathrm{Si}$ that has been exposed to a hydrogen plasma is determined by secondary ionmass spectroscopy (SIMS), a higher hydrogen concentration is found compared to the concentration of hydrogen complexes determined by electrical measurements. This difference is most pronounced close to the sample surface. The additional hydrogen is usually attributed to the formation of hydrogen dimers such as the $\mathrm{H}_{2}$ molecule. It was first proposed by Corbett et al. [7] that molecular hydrogen would be stable in crystalline Si. Calculations by various groups have subsequently confirmed that the stable $\mathrm{H}_{2}$ molecule would be positioned at or near the tetrahedral interstitial $(T)$ site within the Si lattice [8-10]. Many experimental results have been explained in terms of the formation of $\mathrm{H}_{2}$ molecules. The experimental evidence for the presence of the $\mathrm{H}_{2}$ molecule in $\mathrm{Si}$ is however difficult to obtain, due to its electrical neutrality and presumed infrared inactivity. Fortunately, $\mathrm{H}_{2}$ molecules are Raman active and can thus be studied provided the hydrogen concentration is sufficiently high.

Murakami et al. [11] measured a Raman line at 4158 $\mathrm{cm}^{-1}$ in $\mathrm{Si}$ samples treated in hydrogen plasma and 
identified the line as the vibrational excitation of the isolated $\mathrm{H}_{2}$ molecule in $\mathrm{Si}$. It is significant that their reported frequency is within a few $\mathrm{cm}^{-1}$ of the value of $4161 \mathrm{~cm}^{-1}$ for gaseous $\mathrm{H}_{2}$ [12]. By comparison, a Raman line at $3934 \mathrm{~cm}^{-1}$ was reported by Vetterhöffer et al. [13] for the isolated $\mathrm{H}_{2}$ molecule at the $T$ site in hydrogenated GaAs. It is difficult to reconcile these two frequencies with the value in $\mathrm{H}_{2}$ gas. One would firstly expect that the confinement of the $\mathrm{H}_{2}$ molecule when placed in a crystalline solid would result in a downward shift of the Raman frequency from the gaseous value. Secondly, one would anticipate that the vibrational frequency of the $\mathrm{H}_{2}$ molecule in the Si matrix would be even lower than the frequency for $\mathrm{H}_{2}$ in $\mathrm{GaAs}$, in agreement with very recent calculations [14].

Murakami et al. [11] have argued that the $4158 \mathrm{~cm}^{-1}$ Raman signal they have measured comes from the $\mathrm{H}_{2}$ molecule situated at or close to the $T$ site in $\mathrm{Si}$. We have subsequently presented strong evidence for an alternative explanation, namely, that the $\mathrm{H}_{2}$ signal originates from $\mathrm{H}_{2}$ molecules trapped within the voids formed by the hydrogen plasma-induced platelets that are generated during the hydrogen plasma treatment [15]. Annealing studies have shown that the characteristic Raman signal from the platelets and the $4158 \mathrm{~cm}^{-1}$ $\mathrm{H}_{2}$ signal are correlated, exhibiting the same annealing behaviour. This explanation is further supported by our very recent report of a Raman line at $3601 \mathrm{~cm}^{-1}$ in hydrogenated $\mathrm{Si}$, which we attribute to isolated $\mathrm{H}_{2}$ molecules positioned at the $T$ site in $\mathrm{Si}$ [16]. Unlike the $4158 \mathrm{~cm}^{-1}$ hydrogen related Raman line which does not change frequency with temperature, the $3601 \mathrm{~cm}^{-1}$ line shows a very similar temperature dependence to what we have measured for the Raman signal for interstitial $\mathrm{H}_{2}$ in GaAs [17].

In this paper we first present our Raman data of the $\mathrm{H}_{2}$ molecules associated with the platelets in hydrogenated Si. We discuss the strong correlation of this $\mathrm{H}_{2}$ signal with the characteristic Raman signal from the hydrogen platelets. We then present our Raman spectroscopy results for interstitial $\mathrm{H}_{2}$ in $\mathrm{Si}$ and compare it with the recently reported infrared (IR) spectroscopy of hydrogenated Si [18].

\section{Experimental}

Float zone (FZ) as well as Czochralski (CZ) silicon wafers doped with either phosphorus (n-type) or boron (p-type) in a wide range of resistivities $(0.07$ to 2000 $\Omega \mathrm{cm})$ were studied. Hydrogen was introduced into the wafers by exposing them to a remote dc hydrogen plasma at sample temperatures ranging from room temperature to $400^{\circ} \mathrm{C}$ for $30 \mathrm{~min}$ to $8 \mathrm{~h}$. The samples were mounted on a heater stage located downstream from the plasma. The temperature was monitored with a thermocouple mounted next to the sample. No effect of the plasma on the thermocouple reading was detected. The hydrogen pressure was held constant at 1.5 mbar. For some samples the hydrogen atmosphere was replaced by either deuterium, or a mixture consisting of $\mathrm{H}_{2}: \mathrm{D}_{2}(1: 1)$.

Raman measurements were performed at sample temperatures ranging from $4.2 \mathrm{~K}$ to room temperature, using the focused lines of an $\mathrm{Ar}$ or $\mathrm{Kr}$-ion laser for excitation. The incident laser intensity was typically between 50 and $300 \mathrm{~mW}$. The backscattered light, not analysed for its polarisation, was dispersed using a 0.3 $\mathrm{m}$ single grating spectrometer and detected with a cooled $\mathrm{Si}-\mathrm{CCD}$ detector array. Appropriate holographic notch filters were used to reduce the scattered laser light. The full spectral range up to $4500 \mathrm{~cm}^{-1}$ was investigated.

\section{Results}

\subsection{General features of the Raman spectra}

Fig. 1 illustrates the hydrogen related features of a Raman spectrum that are measured after exposure of $0.07 \Omega \mathrm{cm}$ phosphorus-doped $\mathrm{FZ}-\mathrm{Si}$ to the various plasmas at $200^{\circ} \mathrm{C}$. Curve (a) shows two hydrogen related Raman peaks after exposure to a pure $\mathrm{H}_{2}$ plasma. Firstly, the peak measured at $4157 \mathrm{~cm}^{-1}$ is attributed to vibrational excitations of isolated $\mathrm{H}_{2}$ molecules and is equivalent to the $4158 \mathrm{~cm}^{-1}$ peak reported by $\mathrm{Mu}-$ rakami et al. [11]. Its unambiguous identification with $\mathrm{H}_{2}$ is confirmed by exposing the $\mathrm{Si}$ to either a pure $\mathrm{D}_{2}$ plasma (curve (b)) or a plasma containing a $\mathrm{H}_{2}: \mathrm{D}_{2}$ mixture (curve (c)). For the case of the $\mathrm{D}_{2}$ plasma the peak has shifted to $2991 \mathrm{~cm}^{-1}$, while the $\mathrm{H}_{2}: \mathrm{D}_{2}$ mixture gives rise to the lines at $4157 \mathrm{~cm}^{-1}, 2991 \mathrm{~cm}^{-1}$ as well as at $3629 \mathrm{~cm}^{-1}$. These three lines are therefore inter-

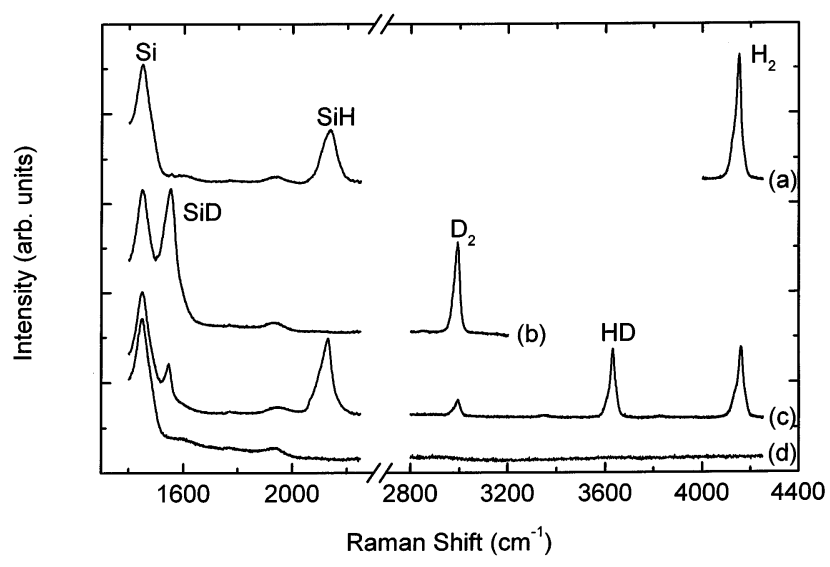

Fig. 1. Raman spectra of a Si:P sample at room temperature, after exposure at $200^{\circ} \mathrm{C}$ for $8 \mathrm{~h}$ to: (a) $\mathrm{H}_{2}$ plasma; (b) $\mathrm{D}_{2}$ plasma; (c) $\mathrm{H}_{2}: \mathrm{D}_{2}$ (50:50) plasma; and (d) no plasma treatment. 
Table 1

Summary of the reported Raman frequencies for $\mathrm{H}_{2}$ in various matrices

\begin{tabular}{|c|c|c|c|c|}
\hline Matrix & $\begin{array}{l}\mathrm{H}_{2} \\
\left(\mathrm{~cm}^{-1}\right)\end{array}$ & $\begin{array}{l}\mathrm{D}_{2} \\
\left(\mathrm{~cm}^{-1}\right)\end{array}$ & $\begin{array}{l}\mathrm{HD} \\
\left(\mathrm{cm}^{-1}\right)\end{array}$ & Reference \\
\hline $\mathrm{Si}$ & $4157 \pm 2$ & $2991 \pm 2$ & $3629 \pm 2$ & $\begin{array}{l}\text { Leitch et al. } \\
{[15]}\end{array}$ \\
\hline $\mathrm{Si}$ & $4158 \pm 3$ & $2990 \pm 2$ & - & $\begin{array}{l}\text { Murakami et } \\
\text { al. [12] }\end{array}$ \\
\hline $\mathrm{H}_{2}$ (gas) & 4161.13 & 2993.55 & 3632.06 & Stoicheff [12] \\
\hline $\mathrm{H}_{2}$ (liquid) & 4153.78 & 2987.99 & 3623.65 & $\begin{array}{l}\text { Bhatnagar et } \\
\text { al. [20] }\end{array}$ \\
\hline $\mathrm{H}_{2}$ (solid) & 4151.8 & 2985.46 & 3621.85 & $\begin{array}{l}\text { Bhatnagar et } \\
\text { al. [20] }\end{array}$ \\
\hline
\end{tabular}

preted as vibrational excitations of isolated $\mathrm{H}_{2}, \mathrm{D}_{2}$, and HD molecules in crystalline $\mathrm{Si}$, respectively. The ratio of the frequencies of the $\mathrm{H}_{2}$ signal to the $\mathrm{D}_{2}$ signal is 1.39 , close to the $\sqrt{ } 2$ value expected from the isotope shift. Finally, curve (d) shows that none of these Raman lines were present in the material before hydrogen-plasma treatment. Note that the $1400 \mathrm{~cm}^{-1}$ peak appearing in each spectrum is an overtone of the principle Si phonon. These spectra therefore give convincing evidence for the presence of $\mathrm{H}_{2}$ molecules in crystalline Si.

The second hydrogen related feature seen in curve (a) of Fig. 1 is the broad peak at $2129 \mathrm{~cm}^{-1}$. By replacing the $\mathrm{H}_{2}$ plasma with either a $\mathrm{D}_{2}$ plasma or a $\mathrm{H}_{2}: \mathrm{D}_{2}$ mixture, the peak shifts to $1450 \mathrm{~cm}^{-1}$. It is therefore identified as the well-known Raman signature associated with the stretching modes of the $\mathrm{SiH}$ bonds that are the building block of the platelets. The structured Raman signal indicates different $\mathrm{Si}-\mathrm{H}$ bonds in the extended platelets. Polarised Raman measurements [19] have indicated that the band in fact consists of two or more lines, and that the relative strengths of the lines depend on the thermal history of the sample.

The results of Fig. 1 are summarised in Table 1, together with the values recently reported by Murakami et al. [11] for $\mathrm{Si}$ and the measured Raman frequencies for $\mathrm{H}_{2}, \mathrm{D}_{2}$ and $\mathrm{HD}$ molecules in the gas, liquid and solid phases $[12,20]$. We were not able to detect the $\mathrm{S}_{0}(1)$ rotational line around $590 \mathrm{~cm}^{-1}$ reported by Fukata et al. [21], in spite of the clearly superior signal-to-noise ratios of our measured vibrational $\mathrm{Ra}$ man frequencies.

The formation of $\mathrm{H}_{2}$ molecules in $\mathrm{CZ}-\mathrm{Si}$ was also studied by measuring the $4157 \mathrm{~cm}^{-1}$ Raman signal after H-plasma treatment. Typical results are presented in Fig. 2 for boron doped (p-type) as well as phosphorus doped (n-type) Si. Essentially no differences in the intensities, line-widths or Raman peak positions were found when comparing the $\mathrm{CZ}-\mathrm{Si}$ with the $\mathrm{FZ} \mathrm{Si}$, for both n-type and p-type Si. Furthermore, an investiga- tion of a wide range of resistivities failed to reveal any dependence of the $\mathrm{H}_{2}$ Raman signal on the doping concentration. From the Raman results it would appear that the formation of the $\mathrm{H}_{2}$ molecules is as efficient in p-type $\mathrm{Si}$ as in n-type $\mathrm{Si}$. This interesting result will presently be contrasted with the formation of interstitial $\mathrm{H}_{2}$ in $\mathrm{Si}$.

Fig. 3 shows the effect of temperature on the 4157 $\mathrm{cm}^{-1} \mathrm{H}_{2}$ Raman line [22]. At room temperature the line-width (FWHM, full-width at half-maximum) is about two orders of magnitude broader than the Raman line for gaseous $\mathrm{H}_{2}$ [12], and is also broad compared to other known hydrogen stretching modes in $\mathrm{Si}$ [23]. The line-shape is asymmetric, with a shoulder on the low frequency side. Reducing the temperature decreases the line-width somewhat (from $26 \mathrm{~cm}^{-1}$ at 295 $\mathrm{K}$ to $18 \mathrm{~cm}^{-1}$ at $7.5 \mathrm{~K}$ ); the peak position and asymmetric line-shape however remain the same. We have been able to resolve the shoulder by a series of isochronal anneals up to $500^{\circ} \mathrm{C}$ [24]. The $\mathrm{H}_{2}$ Raman signal decreases in intensity for annealing temperatures above $400^{\circ} \mathrm{C}$, with the peak position at $4157 \mathrm{~cm}^{-1}$ moving slightly to $4152 \mathrm{~cm}^{-1}$, while the peak at 4129 $\mathrm{cm}^{-1}$ (previously only visible as a shoulder) becomes dominant.

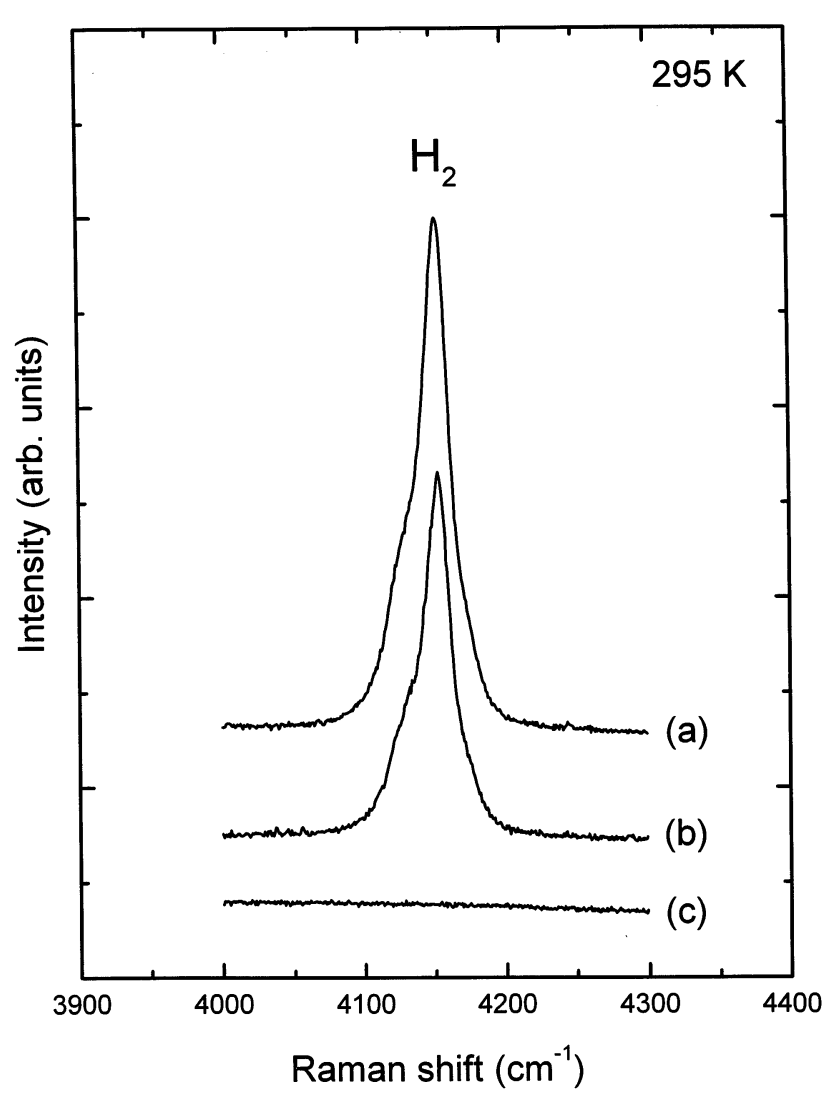

Fig. 2. Spectra of the $4157 \mathrm{~cm}^{-1} \mathrm{H}_{2}$ Raman signal in H-plasma treated $1 \Omega \mathrm{cm} \mathrm{CZ}-\mathrm{Si}$ : (a) B-doped $\mathrm{Si}$; (b) P-doped $\mathrm{Si}$; and (c) P-doped Si (no H-plasma treatment). 


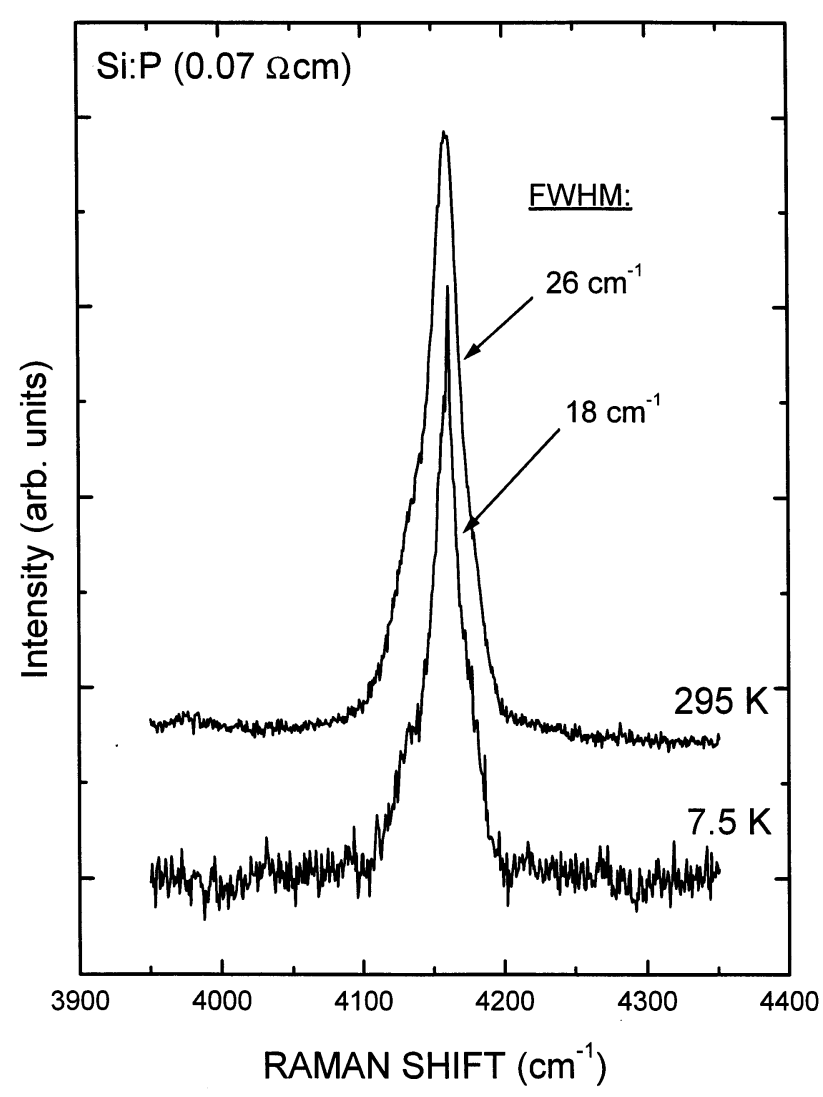

Fig. 3. Temperature dependence of the $4157 \mathrm{~cm}^{-1} \mathrm{H}_{2}$ Raman peak in hydrogen plasma treated Si:P.

\subsection{Origin of the $4157 \mathrm{~cm}^{-1} \mathrm{H}_{2}$ Raman line}

We have checked the depth of the defects giving rise to the $4157 \mathrm{~cm}^{-1} \mathrm{H}_{2}$ Raman signal by etching approximately $50 \mathrm{~nm}$ off a H-plasma treated sample. Fig. 4 summarises the results. We find that both the $\mathrm{SiH}$ and the $\mathrm{H}_{2}$ Raman intensities are reduced, but are still measurable. This indicates that the platelets extend into the $\mathrm{Si}$ at least as deep as the $\mathrm{H}_{2}$ molecules, suggesting that the presence of the $4157 \mathrm{~cm}^{-1} \mathrm{H}_{2}$ line in the $\mathrm{Si}$ is related to the existence of the platelets. An obvious candidate for the locality of the $\mathrm{H}_{2}$ molecules within the Si lattice would be the voids formed by the extended platelets, which are generated during the hydrogen plasma treatment. It is important to note that for all the samples investigated the $\mathrm{SiH}$ Raman signal always accompanies the $4157 \mathrm{~cm}^{-1} \mathrm{H}_{2}$ Raman line.

Further evidence that the $4157 \mathrm{~cm}^{-1} \mathrm{H}_{2}$ line is related to the platelets in the $\mathrm{Si}$ comes from their annealing behaviour. After a series of isochronal anneals, both Raman signals show the same annealing characteristics with an annealing out at the same rate within the range $400-500^{\circ} \mathrm{C}$. Assuming that the annealing of the $\mathrm{SiH}$ and $\mathrm{H}_{2}$ signals obeys first-order kinetics and assuming a jump frequency of $10^{13} \mathrm{~s}^{-1}$, we have obtained an activation energy of $2.3 \mathrm{eV}$ for the process

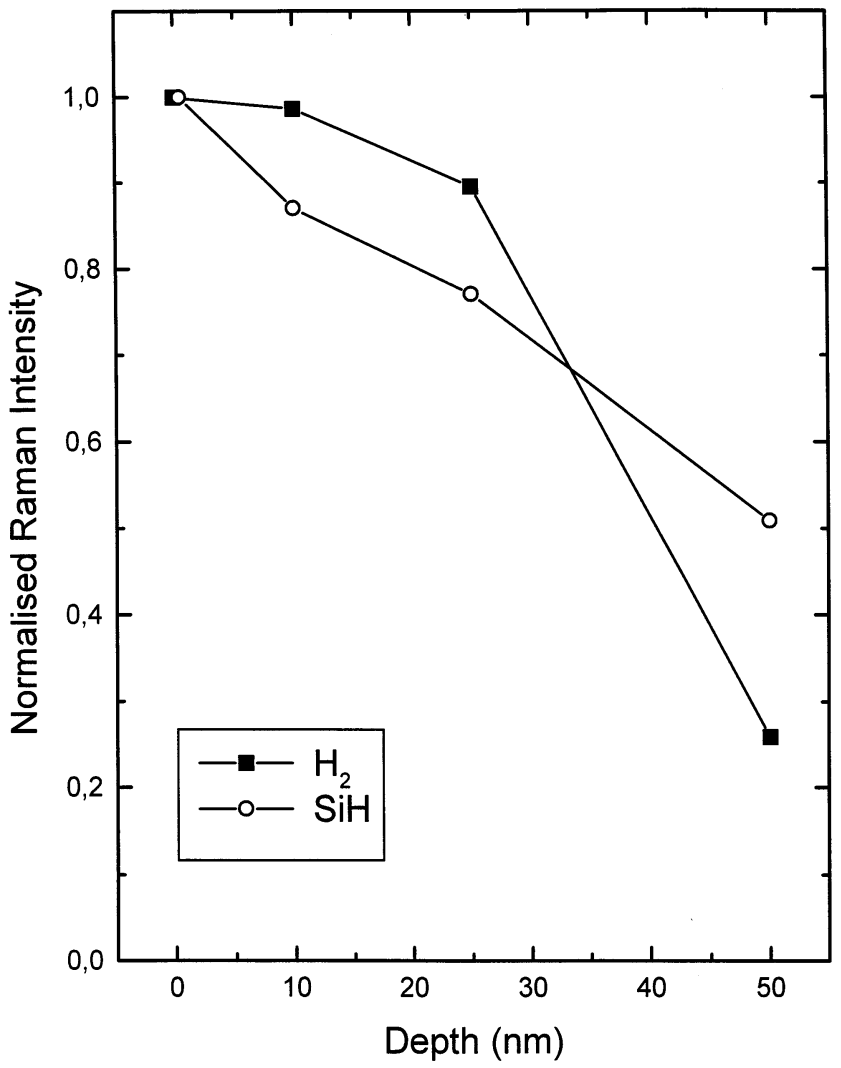

Fig. 4. Depth profiles of the integrated intensities of the $2129 \mathrm{~cm}^{-1}$ platelet signal and the $4157 \mathrm{~cm}^{-1} \mathrm{H}_{2}$ signal in $\mathrm{Si}: \mathrm{P}$.

[15]. It may be noted that Beyer [25], when measuring the effusion of hydrogen from a $\langle 111\rangle \mathrm{Si}$ surface, calculated a free energy of desorption of $2.2 \mathrm{eV}$. As the platelets break up (resulting in a decrease in the $\mathrm{SiH}$ Raman signal), the high concentration of $\mathrm{H}_{2}$ molecules will reduce, either by effusion from the surface, or by diffusing deeper into the material.

Despite the fact that the platelets and the $4157 \mathrm{~cm}^{-1}$ $\mathrm{H}_{2}$ Raman signals are correlated, the optimum temper-

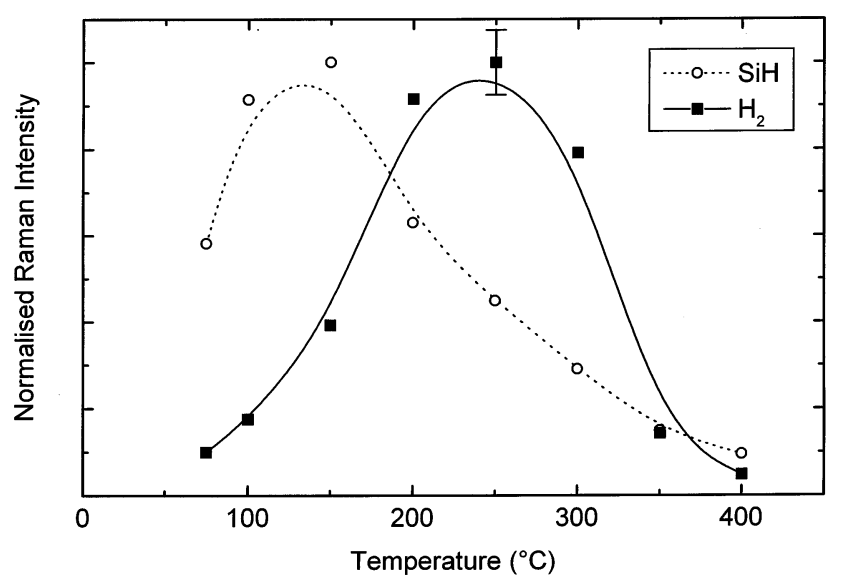

Fig. 5. Dependence of the integrated $\mathrm{SiH}$ and $\mathrm{H}_{2}$ Raman signals in $\mathrm{Si}: \mathrm{P}$ on the sample temperature during hydrogen plasma treatment. 


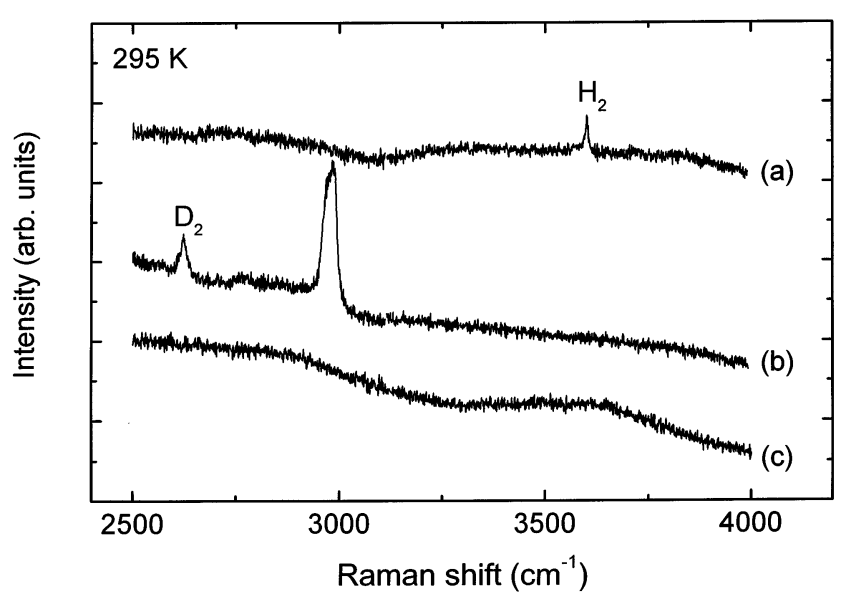

Fig. 6. Room temperature Raman spectra of Si:P $(0.07 \Omega \mathrm{cm})$, after exposure to the following plasmas at $150^{\circ} \mathrm{C}$ for $3 \mathrm{~h}$. Curve (a): $\mathrm{H}_{2}$ plasma; curve (b): $\mathrm{D}_{2}$ plasma; and curve (c): no plasma. Excitation wavelength, $488 \mathrm{~nm}$.

atures for their formation are different. Fig. 5 shows the integrated intensities of the two signals, as function of sample temperature during plasma treatment. In the case of the platelets, the signal reaches a maximum within the range $100-150^{\circ} \mathrm{C}$, in agreement with the earlier Raman studies of Heyman et al. [19]. In this temperature range, the $4157 \mathrm{~cm}^{-1}$ line is rather weak and broad. At higher temperatures $\left(200-300^{\circ} \mathrm{C}\right)$, however, the $4157 \mathrm{~cm}^{-1}$ signal becomes sharp and well defined. Once formed, both signals are stable up to a temperature of around $400^{\circ} \mathrm{C}$, above which they anneal out together as already described.

We explain the results of Fig. 5 as follows: Exposure of the $\mathrm{Si}$ to the H-plasma results in the preferential formation of platelets within the range $100-150^{\circ} \mathrm{C}$. Once formed, these defects become effective traps for any further hydrogen being introduced into the material during the plasma treatment. As more $\mathrm{H}_{2}$ molecules are trapped within the voids formed by the platelets, so the $\mathrm{H}_{2}$ Raman signal at $4157 \mathrm{~cm}^{-1}$ becomes more intense. This explains why the measured $\mathrm{H}_{2}$ Raman frequency of $4157 \mathrm{~cm}^{-1}$ is so close to the reported value of $4161 \mathrm{~cm}^{-1}$ for $\mathrm{H}_{2}$ in the gas phase [12].

\subsection{Formation of $\mathrm{H}_{2}$ molecules at tetrahedral interstitial sites in $\mathrm{Si}$}

In the light of Fig. 5, it is clear that a sufficiently low temperature during plasma treatment is required to minimize the trapping of the $\mathrm{H}_{2}$ by the platelets. On the other hand, one requires a temperature sufficiently high for the atomic hydrogen to be able to diffuse through the $\mathrm{Si}$ and form the molecules. We have found that a plasma temperature of $150^{\circ} \mathrm{C}$ is suitable for the formation of $\mathrm{H}_{2}$ molecules. Fig. 6 shows the room temperature Raman spectra of $\mathrm{Si}$ exposed to the various plasmas at $150^{\circ} \mathrm{C}$ for $3 \mathrm{~h} \mathrm{[16].} \mathrm{A} \mathrm{small} \mathrm{but} \mathrm{clear} \mathrm{signal}$ appears at $3601 \mathrm{~cm}^{-1}$ after treatment in a $\mathrm{H}_{2}$ plasma (curve (a)). Not shown in the spectrum is a larger peak at $4157 \mathrm{~cm}^{-1}$ corresponding to the $\mathrm{H}_{2}$ signal associated with the platelets. Exposure to a $\mathrm{D}_{2}$ plasma results in a peak at $2622 \mathrm{~cm}^{-1}$ (curve (b)). The larger peak at 2991 $\mathrm{cm}^{-1}$ corresponds to the platelet-related $\mathrm{D}_{2}$ signal seen in Fig. 1 (curve (b)). The ratio of the $\mathrm{H}_{2}$ to $\mathrm{D}_{2}$ frequencies is 1.37 , thus providing evidence that these peaks arise from $\mathrm{H}_{2}$ and $\mathrm{D}_{2}$ molecules, respectively. Again, curve (c) shows that these peaks were not measured in a sample that had not been exposed to the plasma. It was not possible to identify the expected HD frequency in a sample that had been exposed to a $\mathrm{H}_{2}: \mathrm{D}_{2}$ plasma, because of the weakness of the signals.

The measured vibrational frequencies for the interstitial $\mathrm{H}_{2}$ molecule are summarised in Table 2, together with the infrared local vibrational mode (LVM) data recently reported by Pritchard et al. [18] and several recent calculations of the frequency. The excellent agreement of the Raman results and the infrared LVM data at $10 \mathrm{~K}$ clearly indicates that we are measuring the same vibrational excitation of the isolated $\mathrm{H}_{2}$ molecule, positioned at the tetrahedral interstitial site in $\mathrm{Si}$. This assignment is also supported by the recent calculations given in Ref. [14,26-28]. The one exception to this is the calculation undertaken by Nakamura et al. [29], who calculated a frequency of $4470 \mathrm{~cm}^{-1}$, a value greater than the known frequency of $4161 \mathrm{~cm}^{-1}$ for $\mathrm{H}_{2}$ molecules in the gas phase.

It must be emphasised that the Raman peaks seen in Fig. 6, although much weaker in intensity are much sharper than the hydrogen-related lines of Fig. 1. Their line-widths (ca. $6 \mathrm{~cm}^{-1}$ ) are of the same order as what has been measured for $\mathrm{H}_{2}$ in GaAs [13]. It was not

Table 2

Summary of the reported vibrational frequencies for $\mathrm{H}_{2}$ at the $T$ site in $\mathrm{Si}$, together with recent calculated frequencies

\begin{tabular}{|c|c|c|c|c|}
\hline Matrix & $\begin{array}{l}\mathrm{H}_{2} \\
\left(\mathrm{~cm}^{-1}\right)\end{array}$ & $\begin{array}{l}\mathrm{D}_{2} \\
\left(\mathrm{~cm}^{-1}\right)\end{array}$ & $\begin{array}{l}\text { HD } \\
\left(\mathrm{cm}^{-1}\right)\end{array}$ & Reference \\
\hline Si $(295 \mathrm{~K})$ & 3601 & 2622 & - & $\begin{array}{l}\text { Leitch et al. } \\
{[16]}\end{array}$ \\
\hline $\mathrm{Si}(10 \mathrm{~K})$ & 3618 & - & - & $\begin{array}{l}\text { Leitch et al. } \\
{[16]}\end{array}$ \\
\hline $\mathrm{Si}(10 \mathrm{~K})$ & 3618.3 & 2642.5 & 3264.8 & $\begin{array}{l}\text { Pritchard et al. } \\
{[18]}\end{array}$ \\
\hline Si (theory) & 3422 & - & - & $\begin{array}{l}\text { Van de Walle } \\
\text { et al. [14] }\end{array}$ \\
\hline Si (theory) & 3708 & 2622 & 3217 & $\begin{array}{l}\text { Hourahine et } \\
\text { al. [26] }\end{array}$ \\
\hline Si (theory) & 3363 & - & - & $\begin{array}{l}\text { Okamoto et al. } \\
\text { [27] }\end{array}$ \\
\hline Si (theory) & 3723 & - & - & Deak [28] \\
\hline Si (theory) & 4470 & - & - & $\begin{array}{l}\text { Nakamura et } \\
\text { al. [29] }\end{array}$ \\
\hline
\end{tabular}




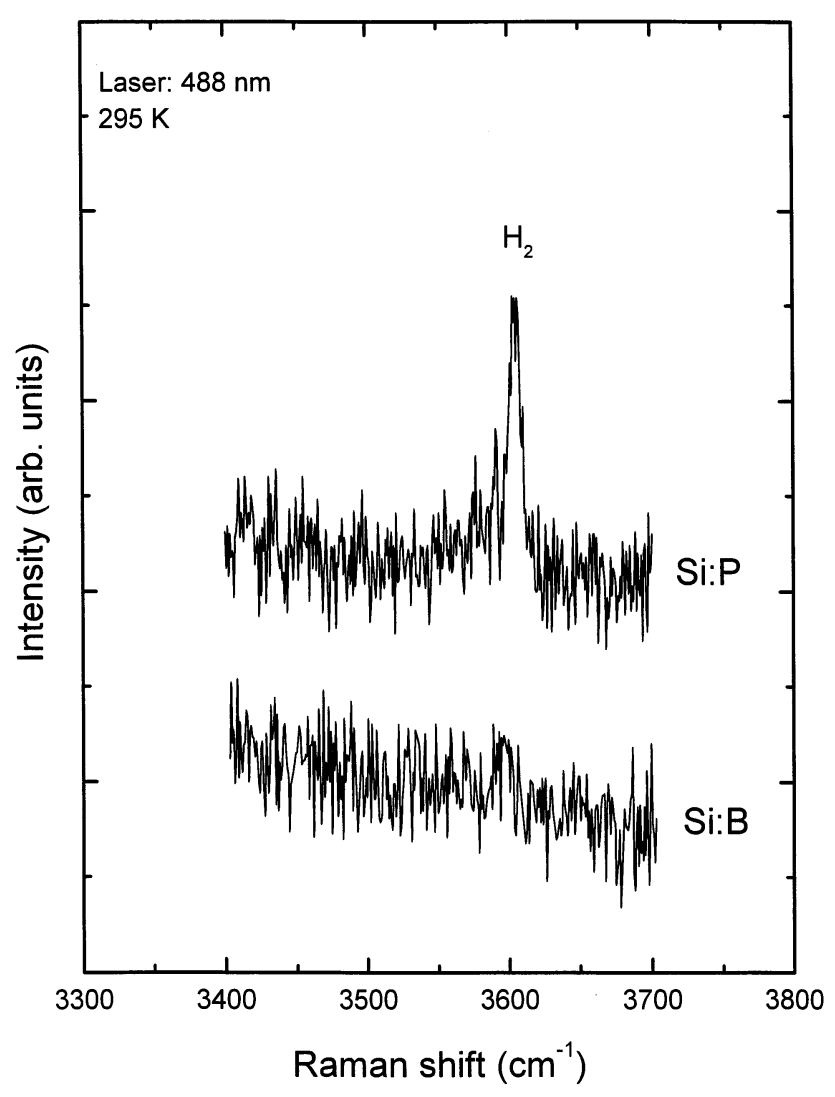

Fig. 7. Raman spectra for (a) $0.07 \Omega \mathrm{cm} \mathrm{Si:P}$ and (b) $1 \Omega \mathrm{cm} \mathrm{Si:B,} \mathrm{after}$ simultaneous exposure to a $\mathrm{H}_{2}$ plasma at $150^{\circ} \mathrm{C}$.

possible however to resolve the splitting due to the para and ortho- $\mathrm{H}_{2}$ rotational states of the vibrational Raman lines, in agreement with the infrared LVM results of Pritchard et al. [18] and the conclusions of Hourahine et al. [26].

Fig. 7 shows the Raman spectra for B-doped $(1 \Omega \mathrm{cm})$ $\mathrm{Si}$ and P-doped $(0.07 \Omega \mathrm{cm}) \mathrm{Si}$, which were simultaneously exposed to a $\mathrm{H}_{2}$ plasma. While the expected $3601 \mathrm{~cm}^{-1}$ interstitial $\mathrm{H}_{2}$ signal was clearly visible in the n-type $\mathrm{Si}$, the signal in the p-type $\mathrm{Si}$ could not be resolved above the noise. This result shows that the charge state of the atomic hydrogen has an important effect on the formation of the $\mathrm{H}_{2}$ molecules. Thus, monitoring $\mathrm{H}_{2}$ formation as a function of Fermi level has the potential to provide new information about the $\mathrm{H}$ charge states.

\subsection{Temperature dependence of the interstitial $\mathrm{H}_{2}$ Raman line}

Fig. 8 shows the temperature dependence of the interstitial $\mathrm{H}_{2}$ Raman peak in $\mathrm{Si}$. As the sample temperature is lowered we see that the $\mathrm{H}_{2}$ Raman frequency increases from $3601 \mathrm{~cm}^{-1}$ at $295 \mathrm{~K}$ to $3618 \mathrm{~cm}^{-1}$ at 10 $\mathrm{K}$, thereby confirming the infrared LVM data [18]. We have measured a similar temperature dependence for the Raman signal of interstitial $\mathrm{H}_{2}$ in GaAs [17]. This may be explained by the thermal expansion coefficient of the host material. Again, this result is in contrast with what was measured for the $4157 \mathrm{~cm}^{-1} \mathrm{H}_{2}$ line (see Fig. 3), where no temperature dependence was observed.

\section{Summary}

We have measured the Raman signal of the $\mathrm{H}_{2}$ molecule in crystalline $\mathrm{Si}$ after exposure to a hydrogen plasma. When hydrogen is introduced into the $\mathrm{Si}$ at temperatures around $150^{\circ} \mathrm{C}$, the $\mathrm{H}_{2}$ molecules are positioned at the tetrahedral interstitial sites within the $\mathrm{Si}$ lattice. The room temperature vibrational frequency is measured to be $3601 \mathrm{~cm}^{-1}$, increasing to $3618 \mathrm{~cm}^{-1}$ at $10 \mathrm{~K}$. The effect of the Si matrix is thus to reduce the vibrational frequency by more than $500 \mathrm{~cm}^{-1}$ from the value of $4161 \mathrm{~cm}^{-1}$ for gaseous $\mathrm{H}_{2}$.

When hydrogen is introduced into the $\mathrm{Si}$ at temperatures in excess of $150^{\circ} \mathrm{C}$, the hydrogen plasma induced platelets act as sinks for the hydrogen, and a strong Raman line at $4157 \mathrm{~cm}^{-1}$ is measured. This is attributed to $\mathrm{H}_{2}$ molecules that have become trapped within the voids created by the platelets. This signal

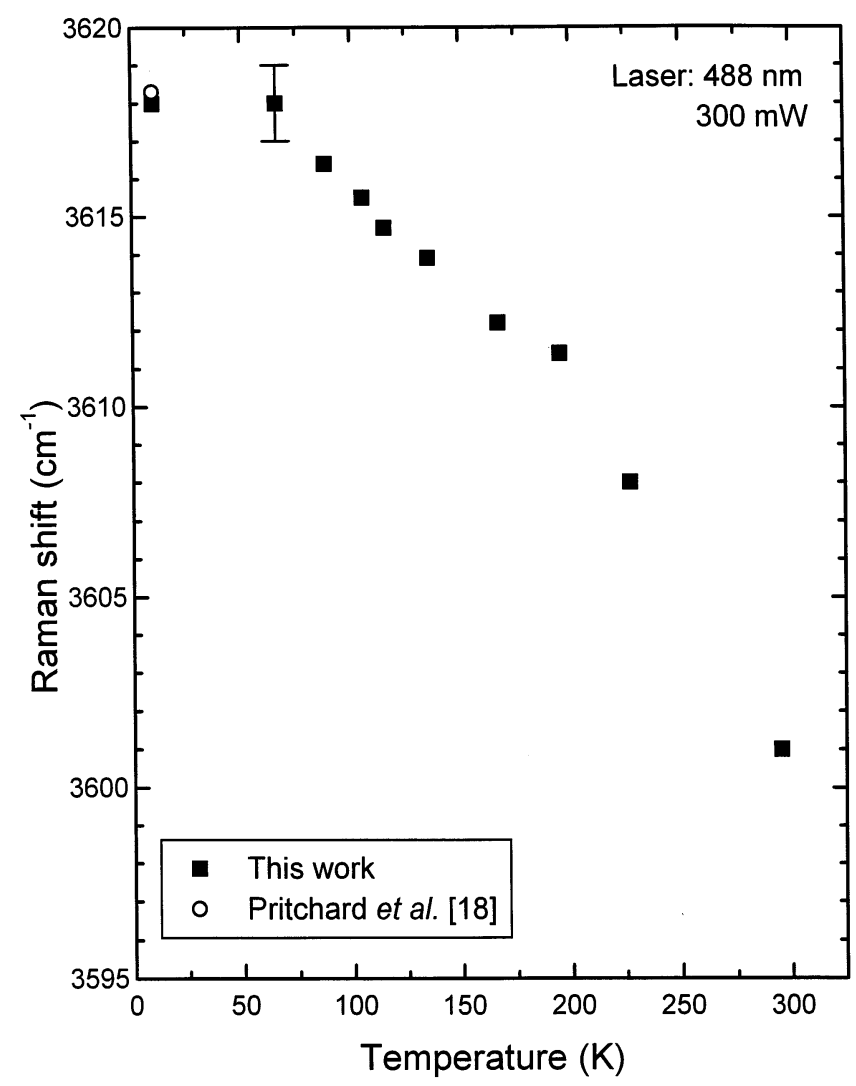

Fig. 8. Temperature dependence of the interstitial $\mathrm{H}_{2}$ Raman line in Si:P $(0.07 \Omega \mathrm{cm})$. Excitation wavelength: $488 \mathrm{~nm}$. 
shows little temperature dependence, and is stable up to about $400^{\circ} \mathrm{C}$, above which both the $\mathrm{H}_{2}$ and the platelet signals anneal out at the same rate.

\section{Acknowledgements}

It is a pleasure to gratefully acknowledge the continued interest and support of Professor H.-J. Queisser, in whose group this work was performed. We also thank S.K. Estreicher and P. Deák for many stimulating discussions. One of us (AWRL) acknowledges the financial support of the South African Foundation for Research Development. The technical assistance of $\mathrm{W}$. Heinz and W. Krause is appreciated.

\section{References}

[1] J.I. Pankove, N.M. Johnson (Eds.), Hydrogen in semiconductors, in Semiconductors and Semimetals, Vol. 34, Treatise Editors R.K. Willardson, A.C. Beer, Academic Press, Boston, 1991.

[2] W.K. Chu, R.H. Kastl, R.F. Lever, S. Mader, B.J. Masters, Phys. Rev. B 16 (1977) 3851.

[3] N.M. Johnson, F.A. Ponce, R.A. Street, R.J. Nemanich, Phys. Rev. B 35 (1987) 4166.

[4] S. Romani, J.H. Evans, Nucl. Instr. Meth. B 44 (1990) 313.

[5] S. Muto, S. Takeda, M. Hirata, Phil. Mag. A 72 (1995) 1057.

[6] P. Deák, C.R. Ortiz, L.C. Snyder, J.W. Corbett, Physica B 170 (1991) 223.

[7] J.W. Corbett, S.N. Sahu, T.S. Shi, L.C. Snyder, Phys. Lett. A 93 (1983) 303.

[8] C.G. Van de Walle, Phys. Rev. B 49 (1994) 4579.

[9] D.J. Chadi, C.H. Park, Phys. Rev. B 52 (1995) 8877.

[10] S.K. Estreicher, Mater. Sci. Eng. R 14 (1995) 319.
[11] K. Murakami, N. Fukata, S. Sasaki, K. Ishioka, M. Kitajima, S. Fujimura, J. Kikuchi, H. Haneda, Phys. Rev. Lett. 77 (1996) 3161.

[12] B.P. Stoicheff, Can. J. Phys. 35 (1957) 730.

[13] J. Vetterhöffer, J. Wagner, J. Weber, Phys. Rev. Lett. 77 (1996) 5409.

[14] C.G. Van de Walle, Phys. Rev. Lett. 80 (1998) 2177.

[15] A.W.R. Leitch, V. Alex, J. Weber, Solid State Commun. 105 (1998) 215.

[16] A.W.R. Leitch, V. Alex, J. Weber, Phys. Rev. Lett. 81 (1998) 421.

[17] A.W.R. Leitch, V. Alex, J. Weber, Phys. Rev. B (1998) (submitted for publication)

[18] R.E. Pritchard, M.J. Ashwin, J.H. Tucker, R.C. Newman, E.C. Lightowlers, M.J. Binns, S.A. McQuaid, R. Falster, Phys. Rev. B 56 (1997) 13118.

[19] J.N. Heyman, J.W. Ager, E.E. Haller, N.M. Johnson, J. Walker, C.M. Doland, Phys. Rev. B 45 (1992) 13363.

[20] S.S. Bhatnagar, E.J. Allin, H.L. Welsh, Can. J. Phys. 40 (1962) 9.

[21] N. Fukata, S. Sasaki, K. Murakami, K. Ishioka, M. Kitajima, S. Fujimura, J. Kikuchi, Jpn. J. Appl. Phys. 35 (1996) 1069.

[22] J. Weber, A.W.R. Leitch, V. Alex, in: H.R. Huff, U. Gösele, H. Tsuya (Eds.), Proceedings of the $8^{\text {th }}$ international symposium on silicon materials science and technology, vols. 98-1, The Electrochemical Society, NJ, 1998, p. 973.

[23] K. Bergman, M. Stavola, S.J. Pearton, J. Lopata, Phys. Rev. B 37 (1988) 2770.

[24] A.W.R. Leitch, V. Alex and J. Weber, in: G. Davies and M.H. Nazaré (Eds.), Proceedings of the 19th international conference on defects in semiconductors, Aveiro, Portugal, 1997, Switzerland: Trans Tech Publications, 1997, p. 241.

[25] W. Beyer, Physica B 170 (1991) 105.

[26] B. Hourahine, R. Jones, S. Öberg, R.C. Newman, P.R. Briddon, E. Roduner, Phys. Rev. B 57 (1998) 12666.

[27] Y. Okamoto, M. Saito, A. Oshiyama, Phys. Rev. B 56 (1997) 10016.

[28] P. Deák (private communication).

[29] K.G. Nakamura, K. Ishioka, M. Kitajima, K. Murakami, Solid State Commun. 101 (1997) 735. 